\title{
Research and Practice of Cultivating Young College Teachers' Teaching Ability Based on Assessment System
}

Lihua Gong

Teaching Quality Control Center of Taishan University

\begin{abstract}
Young teachers, as an important driving force to promote the better development of colleges and universities in the future, their teaching experience and teaching ability can not only play a vital role in the development of the school itself, but also cultivate the country for the society. Skilled talents required. This requires the school to actively seek specific directions for improving the teaching ability of young teachers through the improvement of the evaluation system, so as to enable teachers to get better development and inject fresh and fresh blood into my country's education.
\end{abstract}

Keywords: Teaching Ability; Assessment System; Young Teachers; Training Strategy

Many colleges and universities regard young teachers as the backbone to ensure the successful completion of scientific research and educational work that can be carried out efficiently. Therefore, teachers' teaching ability, ideological values, teaching experience and moral level can have a profound impact on the sustainable development of the school. The assessment and evaluation system is an important content in the management of colleges and universities. The improvement of its evaluation mechanism can not only serve as a motivation for young teachers to continuously improve themselves, but also become a framework for regulating their behavioral awareness. Therefore, whether colleges and universities can establish a perfect assessment system can have an important impact on the overall development of teachers. The author starts with the negative impact of the establishment of an imperfect assessment and evaluation mechanism, looking for a specific way to establish a high-quality college and university assessment and evaluation mechanism, hoping to effectively improve the teacher's teaching experience and teaching ability, while enabling the school to develop better.

\section{The negative impact of the imperfect establishment of the assessment mechanism}

\subsection{Reduce the motivation of teachers}

Many colleges and universities will use the workload of teaching as an important indicator to evaluate whether teachers have completed the assessment standards. Only when the teacher guarantees that the completion of the workload exceeds the prescribed standard can it be regarded as conforming to the assessment and evaluation mechanism. As we all know, young teachers actually participate in a large amount of work, which includes not only the number of hours of classroom teaching activities, but also student guidance, scientific research progress, and practical guidance. For young teachers who have just joined the college, if they want to complete the standards stipulated by the assessment and evaluation mechanism, they need to take a month or so to lead the students to conduct practical training. At the same time, they must also carry out 2 credits of classroom teaching activities at least two . Under this strict assessment standard, not only does the teacher feel the great pressure of work, but the standard for measuring the teaching ability of the teacher based on the evaluation results is also unreasonable, which in turn affects the teacher's enthusiasm for completing the teaching workload while seriously reducing its work enthusiasm .

Copyright (C) 2020 Lihua Gong

doi: $10.18282 /$ le.v9i7.1482

This is an open-access article distributed under the terms of the Creative Commons Attribution Non-Commercial License

(http://creativecommons.org/licenses/by-nc/4.0/), which permits unrestricted non-commercial use, distribution, and reproduction in any medium, provided the original work is properly cited. 


\subsection{Lack of corresponding incentive mechanism}

Many colleges and universities in the design of assessment and evaluation system, the most commonly established standard is to use posts as a watershed, to carry out differentiated assessment of different work content, so do not focus on improving the incentive mechanism. This overly rigid assessment and evaluation mechanism is a serious oversight of the unification of qualitative and quantitative, which in turn makes the overall assessment results difficult to convince teachers. Some schools usually choose to publish their scores in general or simply not to publish the results of the assessment after the assessment of teachers' teaching results is completed. This serious neglect of the guiding practice of the assessment and evaluation mechanism makes it difficult for young teachers to design and improve the self-improvement plan in a targeted manner based on the evaluation results. Many teachers hope that in their continuous efforts, their teaching experience and teaching ability can be effectively improved, and they hope to use higher assessment scores as a motivation to continuously inspire their progress. In the absence of a corresponding evaluation and evaluation incentive mechanism for such schools, not only will teachers gradually lose their enthusiasm for improving themselves, but also their professional and teaching abilities will be affected.

\section{Specific ways to establish high-quality institutions of higher learning assessment}

\subsection{Reasonably formulate teaching workload and mobilize teachers' work enthusiasm}

Colleges and universities need to establish a more complete mechanism when carrying out assessment and evaluation work. According to the actual development of young teachers, the promotion of their teaching abilities is regarded as the key content of assessment, and gradually establish an assessment and evaluation mechanism that is suitable for their teaching needs and development. . For example, as fresh blood that has just joined the school, young teachers give them too heavy tasks, which not only makes it difficult for teachers to use their energy in conducting professional teaching activities, but also seriously affects their enthusiasm for work. Therefore, the school can use the teaching workload as the basic goal of assessment, and the teaching effectiveness, teaching quality and teaching ability as the key indicators to measure the effectiveness of teacher work. This assessment and evaluation system based on the combination of teachers' teaching ability and teaching workload not only requires stricter requirements for their lectures, but also requires higher quality of teachers' teaching. Out of the constraints of heavy teaching workload, teachers can devote more energy to improving their teaching experience and teaching ability, and then in the process of continuous improvement, to ensure the enthusiasm of work.

\subsection{Improve the method of publishing assessment results and establish corresponding incentive mechanisms}

After the evaluation of the teacher's work is completed, the school needs to carefully design the method of publication so as to achieve that the evaluation result becomes the motivation for the teacher's progress and that the teacher can continue to learn without compromising its self-confidence. In the process, to ensure the practical improvement of teaching ability. At the same time, according to the existing assessment and evaluation mechanism, the school also needs to introduce an incentive mechanism into it, and through the analysis of the work needs of young teachers, regularly carry out training activities and teacher exchange activities. This can not only expand the way for teachers to continuously improve themselves, but also enable them to effectively improve their teaching ability in continuous learning and progress, and then get better development under the guidance of perfect assessment and evaluation mechanism.

\section{Conclusion}

When colleges and universities improve the assessment and evaluation mechanism, they need to make an in-depth analysis of the actual situation of young teachers, so that the evaluation work and teachers' teaching ability can be organically coordinated. This can not only help teachers establish the correct professional value concept, but also realize the importance of improving their professional skills and teaching abilities for future development, and then continue to accumulate professional qualities through the learning of new knowledge under the guidance of the school assessment 
and evaluation mechanism. And then grow into high-quality backbone young teacher talents that the school needs.

\section{References}

1. Chen Ying, Liu Jing, Qian Yonggui. Process-oriented design of teaching quality evaluation scheme for college teachers [C]. Sichuan Labor Security Magazine Publishing Co., Ltd. Proceedings of Labor Security Research Conference (4). Sichuan Labor Security Magazine Publishing Co., Ltd.: Sichuan Labor Security Magazine Publishing Co., 2020: 68-71.

2. Liu Li, Zhu Li, Liu Niancai. Research on the identification of university teachers' scientific research evaluation policy from the perspective of target groups_— Based on a questionnaire survey of 20 "double first-class" construction universities[J]. Education Research of Tsinghua University, 2020, 41(02 ): 73-82.

3. Zhang Ermi, Shi Wanbing. Characteristics and Reference of Humanities Science Teachers' Performance Evaluation System in American Universities[J]. Journal of Shenyang Normal University (Social Science Edition), 2020, 44(01): 98-104. 